\title{
Method of removing secondary compression on clay using preloading
}

\author{
Ega Dhianty ${ }^{1, *}$ and Indrasurya B. Mochtar ${ }^{2}$ \\ 1,2 Civil Engineering, Faculty of Civil Engineering Environment and Geo Engineering, Institut \\ Teknologi Sepuluh Nopember, Indonesia
}

\begin{abstract}
Due to external loads, the soft soil will undergo a large compression of both primary and secondary compression. With soil improvement using prefabricated vertical drain (PVD), the time of primary compression becomes shorter so that secondary compression occurs in short time. There has been little research on how to remove secondary compression. Therefore, further investigation of behaviour and method of removing secondary compression is necessary. This research was conducted based on an experimental study of clay consolidation test with a variation of loading time in the laboratory. The results show that there is an empirical correlation among the secondary compression index $\left(\mathrm{C}^{\prime}\right)$, the initial void ratio $\left(\mathrm{e}_{0}\right)$, the void ratio at the end of primary consolidation $\left(\mathrm{e}_{\mathrm{p}}\right)$, and the effective consolidation stress ( $\left.\mathrm{P}^{\prime}\right)$. The correlations obtained from this study are $\mathrm{C} \alpha^{\prime}=\left(0.0072 \mathrm{e}_{0}-0.0067\right) \mathrm{P}^{\prime}$ and $\mathrm{C} \alpha^{\prime}=\left(0.0077 \mathrm{e}_{\mathrm{p}}-0.006\right) \mathrm{P}^{\prime}$. The greater the effective consolidation stress is, the greater the secondary compression index will become. Therefore, in soil improvement secondary compression can be removed by giving an extra load $(\Delta q)$ that causes additional compression to the primary consolidation where the magnitude equals to the expected secondary compression. Then, this $\Delta \mathrm{q}$ could be removed at the end of the primary consolidation.
\end{abstract}

\section{Introduction}

Compression due to soil consolidation is one of the factors that hinder the construction of civil construction on soft soil. The compression of the soil consists of primary consolidation and secondary compression. Secondary compression tends to be neglected because the magnitude is relatively small and it occurs after primary consolidation, which could takes decades or even a hundred years to be completed. However, with the soil improvement using prefabricated vertical drain (PVD), the time of primary compression can be accelerated so that secondary compression occurs in a short time. This will certainly affect the stability of the building.

The magnitude of secondary compression can be predicted using the secondary compression index $\left(\mathrm{C} \alpha^{\prime}\right)$ parameter where $\mathrm{C} \alpha^{\prime}=\mathrm{C} \alpha /\left(1+\mathrm{e}_{\mathrm{p}}\right), \mathrm{C} \alpha$ is the secondary compression coefficient obtained from Oedometer test, [6]. Therefore, an empirical correlation to obtain a $\mathrm{C} \alpha$ ' value is required. There is an empirical correlation among the secondary compression

\footnotetext{
*Corresponding author: egadhianty12@gmail.com
} 
index $\left(\mathrm{C} \alpha^{\prime}\right)$, the initial void ratio $\left(\mathrm{e}_{0}\right)$, the liquid limit $(\mathrm{LL})$, and the effective consolidation stress $\left(\mathrm{P}^{\prime}\right)$, where $\mathrm{C} \alpha^{\prime}=\left(0.013 \mathrm{e}_{0}-0,000062 \mathrm{LL}-0.003\right) \mathrm{P}^{\prime}$, [1]. From this equation, the liquid limit (LL) has a very small effect on the secondary compression index $(\mathrm{C} \alpha$ '), so that the liquid limit parameters (LL) is negligible and further research is needed to complete the equation of the secondary compression index.

Until currently, the soil settlement due to secondary compression on the road is overcome by periodical maintenance every few years. However, such maintenance could not be applied to buildings when secondary compression occurs, therefore there should be a way to overcome it. The secondary compression index $\left(\mathrm{C} \alpha^{\prime}\right)$ is affected by the effective consolidation stress ( $\left.\mathrm{P}^{\prime}\right)$. The greater the effective consolidation stress is, the greater the secondary compression index will become, [1]. Based on the statement, the method of removing the secondary compression by providing an additional stress $(\Delta \mathrm{P})$ is required. This paper proposed solution of such problem.

\section{Materials and research methods}

This study was conducted based on an experimental study in a laboratory consisting of Volumetric and Gravimetric, Atterberg Limits, and Oedometer tests. The material used is disturbed clay in Surabaya which is then made into remoulded samples with 3 different soil consistencies, i.e. very soft, soft, and medium. This is conducted to obtain a homogeneous soil sample. The clustering of soil consistencies in the remoulded sample is based on the Undrained Shear Strength (Cu) [8], as presented in Table 1.

Table 1. Soil consistencies for soil that dominant of clay and silt [8].

\begin{tabular}{|c|c|c|}
\hline \multirow{2}{*}{ Soil Consistencies } & \multicolumn{2}{|c|}{ Undrained Shear Strength, Cu } \\
\cline { 2 - 3 } & $\mathbf{k P a}$ & $\mathbf{t o n} / \mathbf{m}^{\mathbf{2}}$ \\
\hline Very Soft & $0-12.5$ & $0-1.25$ \\
\hline Soft & $12.5-25$ & $1.25-2.5$ \\
\hline Medium & $25-50$ & $2.5-5$ \\
\hline Stiff & $50-100$ & $5.0-10$ \\
\hline Very Stiff & $100-200$ & $10-20$ \\
\hline Hard & $>200$ & $>20.0$ \\
\hline
\end{tabular}

The first step in laboratory test is to test the Atterberg Limits on the material to determine the value of the liquid limit (LL) which will be used as a guideline for making remoulded samples.

After the liquid limit (LL) value is obtained, the remoulded sample is made with a certain consistency using a modified Oedometer. For the sample with very soft and soft consistencies, the sample is made of slurry form where the water content of the slurry is twice the liquid limit, then consolidated until the reduction is completed with a load of $0.55 \mathrm{~kg} / \mathrm{cm}^{2}$ for very soft consistencies, a load of $1.5 \mathrm{~kg} / \mathrm{cm}^{2}$ for soft consistencies, and a load of 3.7 $\mathrm{kg} / \mathrm{cm}^{2}$ for medium consistencies. After the representing samples very soft, soft, and medium consistencies are formed, vane shear and unconfined compression tests are performed to determine the value of its undrained shear strength $(\mathrm{Cu})$.

After each type of sample is obtained, the Volumetric and Gravimetric tests and the Oedometer tests are performed. The Oedometer tests was conducted in stages with load: 0.25 ; $0.5 ; 1 ; 2 ; 4 ; 8 \mathrm{~kg} / \mathrm{cm}^{2}$ with two variations of loading time that are 24 hours/loading and 128 hours/loading.

After obtaining the consolidation parameter value, statistical analysis with regression was then conducted and compression calculations were obtained to determine the empirical 
correlation of the secondary compression index $\left(\mathrm{C} \alpha^{\prime}\right)$ and the method of removing secondary compression.

\section{Results and discussion}

\subsection{Soil parameters obtained from laboratory tests}

Soil consistencies in this study was chosen based on consistencies representing the compressible layer presented in Table 2. After each type of sample is formed, Volumetric and Gravimetric tests and Oedometer tests is performed twice in each sample to obtain more reliable results. The soil parameters of the test results are presented in Table 2. The Oedometer tests results which is used for statistical analysis of the empirical correlation to determine the secondary compression index $\left(\mathrm{C}^{\prime}\right)$ which consist of the secondary compression coefficient $(\mathrm{C} \alpha)$, the initial void ratio $\left(\mathrm{e}_{0}\right)$, the void ratio at the end of primary consolidation $\left(\mathrm{e}_{\mathrm{p}}\right)$, and the effective consolidation stress $\left(\mathrm{P}^{\prime}\right)$, not shown in this paper.

Table 2. Soil parameters.

\begin{tabular}{|l|c|c|c|}
\hline & Very Soft & Soft & Medium \\
\hline$\gamma_{\text {sat }}\left(\mathrm{g} / \mathrm{cm}^{3}\right)$ & 1.426 & 1.483 & 1.700 \\
\hline$\gamma_{\mathrm{d}}\left(\mathrm{g} / \mathrm{cm}^{3}\right)$ & 0.705 & 0.771 & 1.063 \\
\hline $\mathrm{e}_{0}$ & 1.380 & 1.265 & 1.050 \\
\hline $\mathrm{Wc}(\%)$ & 102.25 & 92.46 & 60 \\
\hline $\mathrm{Gs}$ & 2.616 & 2.616 & 2.616 \\
\hline $\mathrm{Cu}(\mathrm{kPa})$ & 6.0 & 14.8 & 36.5 \\
\hline $\mathrm{Atterberg} \mathrm{Limits}$ & \multicolumn{3}{|l}{} \\
\hline $\mathrm{LL}(\%)$ & 107.51 & 107.51 & 107.51 \\
\hline $\mathrm{PL}(\%)$ & 42.63 & 42.63 & 42.63 \\
\hline $\mathrm{PI}(\%)$ & 64.88 & 64.88 & 64.88 \\
\hline $\mathrm{Consolidation}$ & 0.763 & 0.723 & 0.658 \\
\hline $\mathrm{Cc}$ & 0.203 & 0.197 & 0.187 \\
\hline $\mathrm{Cs}$ & 0.000108 & 0.000159 & 0.000181 \\
\hline $\mathrm{C}_{\mathrm{v}}\left(\mathrm{cm}^{2} / \mathrm{s}\right)$ & 0.0301 & 0.0284 & 0.0191 \\
\hline $\mathrm{C} \alpha$ & \multicolumn{3}{|l}{} \\
\hline
\end{tabular}

\subsection{Empirical correlation of the secondary compression index as a function of the void ratio and the effective consolidation stress}

The empirical correlation to obtain the parameters of the secondary compression index $\left(\mathrm{C} \alpha^{\prime}\right)$ is done by studying the relationship among the secondary compression index $\left(\mathrm{C}^{\prime}\right)$, the initial void ratio $\left(\mathrm{e}_{0}\right)$, the void ratio at the end of primary consolidation $\left(\mathrm{e}_{\mathrm{p}}\right)$ and the effective consolidation stress ( $\left.\mathrm{P}^{\prime}\right)$. To find such relationships, statistical analysis using linear and exponential regression is done to obtain reliable prediction results. This study consisted of two regression groups, the first group is $\mathrm{C} \alpha^{\prime}-\mathrm{e}_{0}-\mathrm{P}^{\prime}$ (Figure 1), and the second group is $\mathrm{C} \alpha$ ' $-\mathrm{e}_{\mathrm{p}}-\mathrm{P}^{\prime}$ (Figure2).

From the statistical analysis, it is found that the ratio between the secondary compression index and the effective consolidation stress $\left(\mathrm{C}^{\prime} / \mathrm{P}^{\prime}\right)$ is directly proportional to $\mathrm{e}_{0}$ and $\mathrm{e}_{\mathrm{p}}$. Figure 1 shows that the greater the initial void ratio is, the greater value of $\mathrm{C} \alpha$ ' $/ \mathrm{P}^{\prime}$ will become, where the coefficient of determination is $\mathrm{R}=0.873-0.888$ is obtained, which means that $87.3 \%-88.8 \%$ of the initial void ratio can explain the magnitude of $\mathrm{C} \alpha^{\prime} / \mathrm{P}^{\prime}$, and the rest is explained by other variables, [1]. Figure 2 shows that the greater the void ratio at the end of primary consolidation is, the greater value of $\mathrm{C} \alpha^{\prime} / \mathrm{P}^{\prime}$ ' will become, where the coefficient of 
determination is $\mathrm{R}=0.910-0.914$ which means that $91 \%-91.4 \%$ of the void ratio at the end of primary consolidation can explain the magnitude of $\mathrm{C} \alpha^{\prime} / \mathrm{P}^{\prime}$, and the rest is explained by other variables. The result of the correlation between $\mathrm{C} \alpha, \mathrm{e}_{0}, \mathrm{e}_{\mathrm{p}}, \mathrm{P}^{\prime}$ can be seen in Table 3 .

The initial void ratio $\left(\mathrm{e}_{0}\right)$ has a linear relationship to the void ratio at the end of primary consolidation $\left(e_{p}\right)$ as shown in Figure 3 . The greater $e_{0}$ is, the greater $e_{p}$ will become. From the result of regression analysis, the value of coefficient determination $\mathrm{R}=0.961$ is obtained. This indicates that $96.1 \%$ of $\mathrm{e}_{0}$ can explain the magnitude of $\mathrm{e}_{\mathrm{p}}$ and the rest is explained by other variables. The value of the coefficient determination $\mathrm{R}$ approaching 1 indicates a strong correlation.

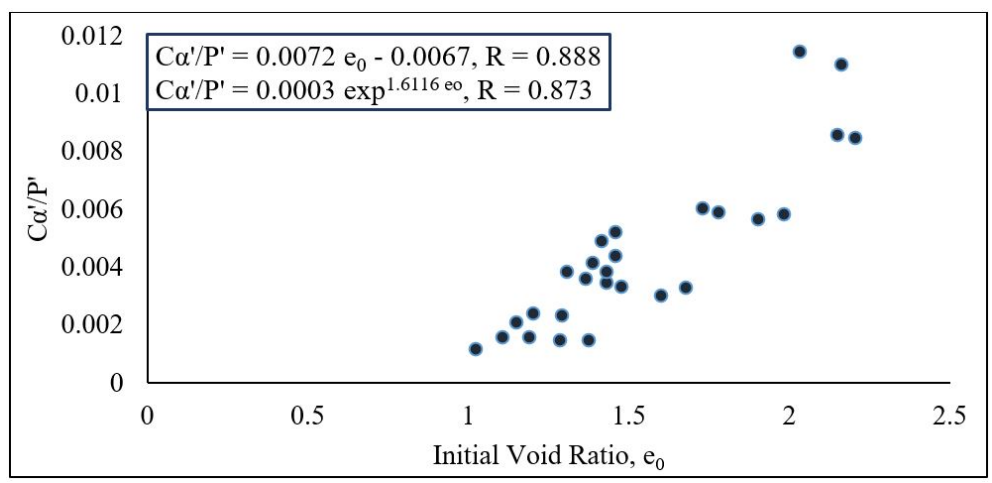

Fig. 1. The relationship between the initial void ratio and $\mathrm{C}^{\prime} / \mathrm{P}^{\prime}$.

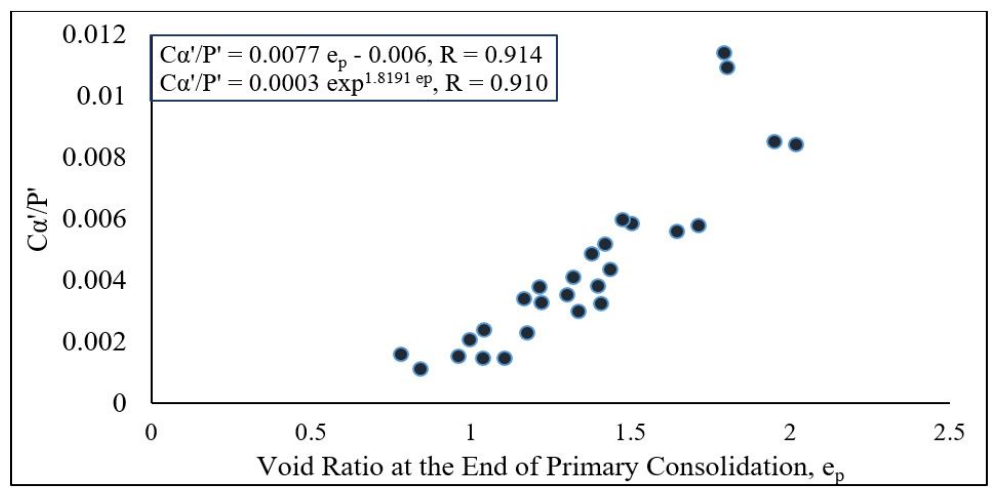

Fig. 2. The relationship between the void ratio at the end of primary consolidation and $\mathrm{C} \alpha^{\prime} / \mathrm{P}^{\prime}$.

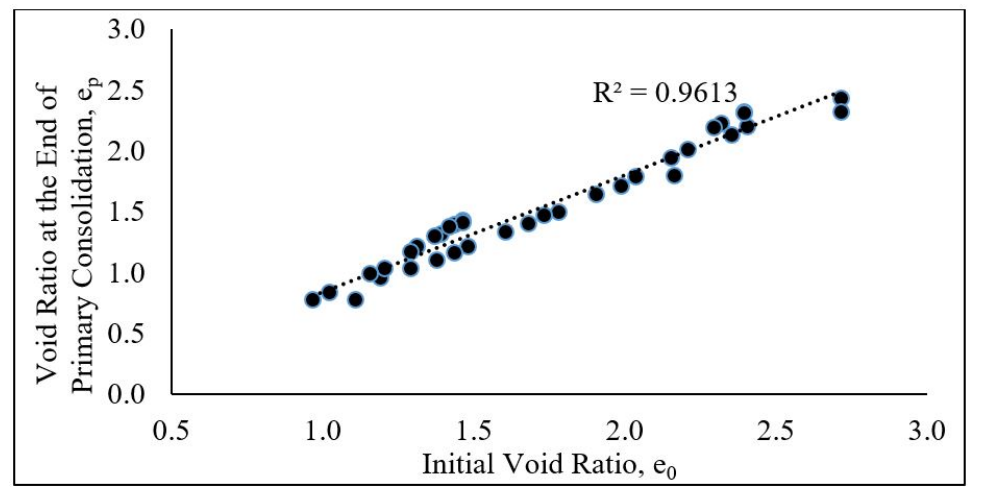

Fig. 3. The relationship between the initial void ratio and the void ratio at the end of primary consolidation. 
Table 3. The correlation between the secondary compression index $\left(\mathrm{C} \alpha^{\prime}\right)$, the void ratio (e), and the effective consolidation stress (P').

\begin{tabular}{|l|c|l|}
\hline \multicolumn{1}{|c|}{ Correlation } & \multicolumn{1}{c|}{$\mathbf{R}$} & \multicolumn{1}{|c|}{ Regression } \\
\hline $\mathrm{C} \alpha^{\prime}=\left(0.0072 \mathrm{e}_{0}-0.0067\right) \mathrm{P}^{\prime}$ & 0.888 & Linear \\
\hline $\mathrm{C} \alpha^{\prime}=\left(0.0003 \mathrm{exp}^{1.6116 \mathrm{eo}}\right) \mathrm{P}^{\prime}$ & 0.873 & Exponential \\
\hline $\mathrm{C} \alpha^{\prime}=\left(0.0077 \mathrm{e}_{\mathrm{p}}-0.006\right) \mathrm{P}^{\prime}$ & 0.914 & Linear \\
\hline $\mathrm{C} \alpha^{\prime}=\left(0.0003 \exp ^{1.8191 \mathrm{ep}}\right) \mathrm{P}^{\prime}$ & 0.910 & Exponential \\
\hline
\end{tabular}

The use of linear and exponential regression analysis on the relationship between the secondary compression index $\left(\mathrm{C} \alpha^{\prime}\right)$, the void ratio (e), and the effective consolidation stress (P') yielded a coefficient of determination (R) not far from each other. However, to obtain reliable correlation predictions, regression is obtained with the coefficient of determination $\mathrm{R}$ closest to 1 . From the correlation in Table 3, the $\mathrm{R}$ value closest to 1 is the linear regression where $\mathrm{R}=0.888$ for the relationship $\mathrm{C} \alpha^{\prime}-\mathrm{e}_{0}-\mathrm{P}^{\prime}$ and $\mathrm{R}=0.914$ for the relationship $\mathrm{C} \alpha^{\prime}-\mathrm{e}_{\mathrm{p}}$ - P'. So in this research the empirical correlation was obtained to get the value of the secondary compression index $\left(\mathrm{C} \alpha^{\prime}\right)$ shown in equation 1 and 2 below.

$$
\begin{aligned}
& C \alpha^{\prime}=\left(0.0072 e_{0}-0.0067\right) P^{\prime} \\
& C \alpha^{\prime}=\left(0.0077 e_{p}-0.006\right) P^{\prime}
\end{aligned}
$$

In laboratory tests, the effective consolidation stress (P') causes soil consolidation, which in the consolidation tests is the total stress of the effective overburden stress (Po') with the stress due to the external load $(\Delta \mathrm{P})$. But basically, the cause of consolidation is the stress due to the external load $(\Delta \mathrm{P})$ since the amount of Po' in the consolidation tests itself is very small, so it is mentioned that $\mathrm{P}^{\prime}=\mathrm{Po}^{\prime}+\Delta \mathrm{P}$. Whereas in the calculation of the prediction of secondary compression, the effective consolidation stress parameters ( $\left.\mathrm{P}^{\prime}\right)$ mentioned in equations 1 and 2 is the value of the addition of stress due to the external load $(\Delta \mathrm{P})$, because in the field that causing soil consolidation is external load.

To determine the validity of the empirical correlation of the secondary compression index $(\mathrm{C} \alpha$ '), equations 1 and 2, laboratory results, and the Alihudien and Mochtar (2009) equations are compared (Figure 4). Figure 4 shows that the value of the secondary compression index $\left(\mathrm{C} \alpha^{\prime}\right)$ of equations 1 and 2, Alihudien and Mochtar (2009), and the laboratory results are not much different. But equation 1 and 2 are closer to the laboratory results than the Alihudien and Mochtar (2009) equations. So equation 1 and 2 can be used to predict secondary compression.

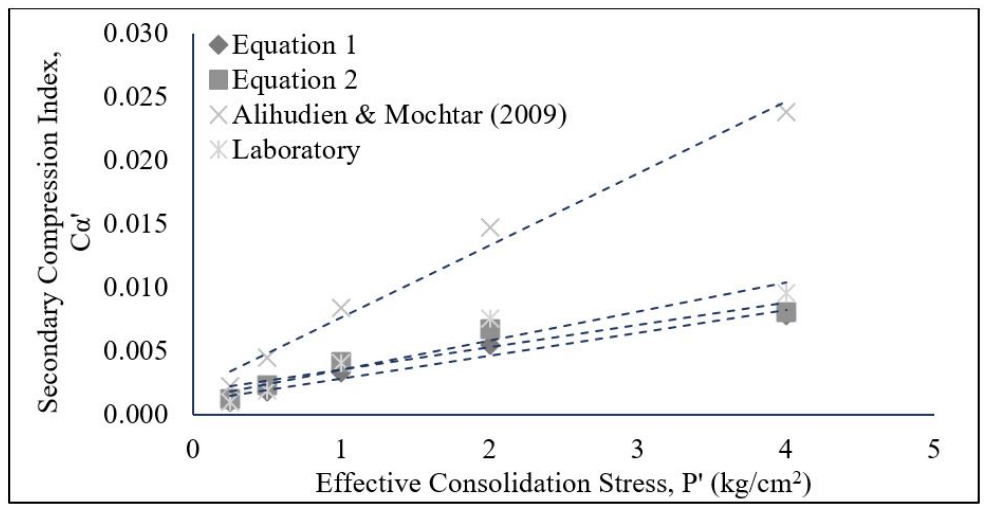

Fig. 4. Comparison of empirical correlation value to data obtained from laboratory. 


\subsection{Method of removing secondary compression}

Based on the empirical correlation of the secondary compression index ( $\mathrm{C} \alpha$ ') by the test results (equations 1 and 2), the value of $\mathrm{C}^{\prime}$ ' is influenced by the effective consolidation stress $\left(\mathrm{P}^{\prime}\right)$. The greater the value of $\mathrm{P}^{\prime}$ is then the greater $\mathrm{C} \alpha$ ' will become. Based on the statement, the secondary compression can be removed by providing an additional stress $(\Delta \mathrm{P})$. The secondary compression is significantly reduced when soils are over consolidated to moderate levels, indicating that the use of preload is greater than the final embankment/structural load, this is an effective method of reducing secondary compression, $[3,4,7,11]$. The secondary compression coefficient $(\mathrm{C} \alpha)$ decreased significantly with an increase in the over consolidation ratio (OCR), so pre-consolidation is an effective method of removing secondary compression, [5].

In this study, secondary compression can be removed along with preloading at the time of removal of the primary consolidation. Secondary compression can be removed by giving an extra load $(\Delta q)$ that causes additional compression to the primary consolidation with the magnitude equals to the expected secondary compression. Then, this $\Delta \mathrm{q}$ could be removed at the end of the primary consolidation. So that after soil improvement with preloading is completed, there is no more settlement caused by primary consolidation and secondary compression.

The extra load $(\Delta q)$ during preloading will make the soil become more compressive and that increases undrained shear strength value $(\mathrm{Cu})$. The increasing value of $\mathrm{Cu}$ causes the secondary compression index $(\mathrm{C} \alpha$ ') to be smaller. So that the extra load $(\Delta \mathrm{q})$ at the time of preloading can eliminate the secondary compression at a certain time period. If the temporary load exceeds the final load of construction then the overload refers to the extra load (surcharge), when the extra load exceeds the workload, the ground will be in over consolidated condition and secondary compression for over consolidated soil will be much smaller than the ground that is normally consolidated, [10].

The steps of soil improvement to removing primary consolidation and secondary compression by preloading methods are as follows:

1. Calculate the primary consolidation $\left(\mathrm{S}_{\mathrm{c}}\right)$ and secondary compression $\left(\mathrm{S}_{\mathrm{s}}\right)$ in the compressible soil according to the variation of the specified final load of embankment $\left(\mathrm{q}_{\text {final }}\right)$. $\mathrm{q}_{\mathrm{final}}$ is the embankment load after the soil is compressed. An embankment after undergoing compression on the ground will undergo a weight change, because during the settlement some part of the embankment is under groundwater, [9]. Primary consolidation can be calculated by the commonly used equation where calculations are differentiated based on over consolidation ratio (OCR) [2], whereas the magnitude of secondary compression occurring at a given time can be predicted using general formulation $\mathrm{S}_{\mathrm{s}}=$ $\mathrm{C} \alpha^{\prime} \mathrm{H} \log \left(\mathrm{t}_{2} / \mathrm{t}_{1}\right)$, where: $\mathrm{C} \alpha^{\prime}$ is the secondary compression index which can be calculated by using equations 1 and $2, \mathrm{H}$ is the thickness of the compressible layer, $\mathrm{t}_{2}$ is the time occurrence of secondary compression, and $t_{1}$ is the time of completion of primary consolidation, [2].

2. Create a graph of the relationship between settlement and final load of embankment ( $\left.\mathrm{q}_{\text {final }}\right)$. The graph consists of two curves, i.e. the primary consolidation curves and the total of primary and secondary compression curves (Figure 5).

3. Create a graph of the relationship between the final load of embankment $\left(\mathrm{q}_{\text {final }}\right)$ and the initial height of embankment $\left(\mathrm{H}_{\text {initial }}\right)$ due to the primary consolidation (Figure 6$) . \mathrm{H}_{\text {initial }}$ is the initial height of embankment before primary consolidation occurs. Because of weight change factors when settlement occurs, the $\mathrm{H}_{\text {initial }}$ can be calculated using the following equation 3 :

$$
H_{\text {initial }}=\frac{q_{\text {final }}+S c\left(\gamma_{\text {embankment }}-\gamma^{\prime}{ }_{\text {embankment }}\right)}{\gamma_{\text {embankment }}}
$$


where, $\gamma_{\text {embankment }}=$ unit weight of embankment and $\gamma^{\prime}$ embankment $=$ effective unit weight of embankment, [9].

4. Create a graph of the relationship between $\mathrm{H}_{\text {initial }}$ and $\mathrm{H}_{\text {final }}$ embankment due to the primary consolidation (Figure 7). $\mathrm{H}_{\text {final }}$ is the final height of embankment after primary consolidation occurs $\left(\mathrm{H}_{\text {final }}=\mathrm{H}_{\text {initial }}-\mathrm{S}_{\mathrm{c}}\right)$, [9].

5. Calculate the extra load of embankment $(\Delta q)$ to remove the secondary compression on the graph of the relationship between settlement and the final load of embankment $\left(\mathrm{q}_{\text {final }}\right)$ presented in Figure 5. $\Delta \mathrm{q}$ is obtained through the intersection of the total of primary and secondary compression $\left(\mathrm{S}_{\text {total }}\right)$ with final load of embankment $\left(\mathrm{q}_{\text {final1 }}\right)$ which is then drawn as a straight line up to cut the primary consolidation curves $\left(\mathrm{S}_{\mathrm{c}}\right)$. Then from the intersection of the primary consolidation curves, drawn a straight line to the left to find out the new final load of embankment $\left(\mathrm{q}_{\text {final2 }}\right)$. So that the extra load $(\Delta \mathrm{q})$ needed to remove the secondary compression is $\Delta \mathrm{q}=\mathrm{q}_{\text {final2 }}-\mathrm{q}_{\text {final1. }}$. The $\Delta \mathrm{q}$ value will be unloaded after the soil improvement is completed.

6. The value of the new final load of embankment $\left(\mathrm{q}_{\mathrm{fina} 2}\right)$ obtained from the previous calculation, is inputted into the graph of the relationship between $q_{\text {final }}$ and $H_{\text {initial }}$ due to the primary consolidation (Figure 6) to find the $\mathrm{H}_{\text {initial }(\mathrm{p}+\mathrm{s})}$. $\mathrm{H}_{\text {initial }(\mathrm{p}+\mathrm{s})}$ is the initial height of embankment which can eliminate the compression of the primary consolidation as well as the secondary compression.

7. After $\mathrm{H}_{\text {initial }(\mathrm{p}+\mathrm{s})}$ is obtained, $\mathrm{H}_{\mathrm{final}(\mathrm{p}+\mathrm{s})}$ is then calculated. $\mathrm{H}_{\mathrm{final}(\mathrm{p}+\mathrm{s})}$ is the final height of embankment after primary consolidation and secondary compression occurs. $\mathrm{H}_{\text {final }(\mathrm{p}+\mathrm{s})}$ is obtained from the equation on the graph of the relationship of $\mathrm{H}_{\text {initial }}$ and $\mathrm{H}_{\text {final }}$ due to the primary consolidation (Figure 7). Then $\mathrm{H}_{\text {final }(\mathrm{p}+\mathrm{s})}$ shall be reduced by the extra load $(\Delta \mathrm{q})$ because it is unloaded after the soil improvement is completed. So the final height of embankment in the field after the primary consolidation and secondary compression occurs is $\mathrm{H}_{\text {final-field }}=\mathrm{H}_{\text {final }(\mathrm{p}+\mathrm{s})}-\left(\Delta \mathrm{q} / \gamma_{\text {embankment }}\right)$.

8. This study provided the calculation and graphing steps used to remove the primary consolidation as well as the secondary compression occurring at any given time. The equations in each graph of Figure 5 to 8 can be changed according to the soil parameters and external load in each different location.

The following examples illustrate the use of the method of removing the secondary compression with preloading. The soil parameters used are laboratory test result parameters presented in Table 2 previously. The soil is modelled with a thickness of $15 \mathrm{~m}$ of compressible layer, consisting of 4 soil layers with 3 soil consistencies, i.e. the first is $2 \mathrm{~m}$ of medium consistency layers, followed by $3 \mathrm{~m}$ of very soft consistency layers, $5 \mathrm{~m}$ of soft consistency layers, and $5 \mathrm{~m}$ of medium consistency layers. The width of the embankment is assumed to be 40 meters with a slope of $1: 2$ and $\gamma_{\mathrm{sat}}=1.9 \mathrm{t} / \mathrm{m}^{3}$. The time of completion of the primary consolidation using PVD is 6 months. While the time of occurrence of the secondary compression reviewed is 25 years. Primary consolidation is calculated based on normally consolidated conditions because in this laboratory observation uses a remoulded sample. The soil settlement are calculated based on final load variations of embankment i.e. $5 \mathrm{t} / \mathrm{m}^{2}, 10$ $\mathrm{t} / \mathrm{m}^{2}, 15 \mathrm{t} / \mathrm{m}^{2}, 20 \mathrm{t} / \mathrm{m}^{2}$, and $25 \mathrm{t} / \mathrm{m}^{2}$.

The calculation results of the soil settlement, $\mathrm{H}_{\text {initial }}$, and $\mathrm{H}_{\text {final }}$ with $\mathrm{q}_{\text {final }}$ variations can be seen in the graph of the relationship between soil settlement with $\mathrm{q}_{\text {final }}$ (Figure 5), the graph of the relationship between $\mathrm{q}_{\text {final }}$ with $\mathrm{H}_{\text {initial }}$ (Figure 6), and the graph of the relationship between $\mathrm{H}_{\text {initial }}$ with $\mathrm{H}_{\text {final }}$ (Figure 7) as follows: 


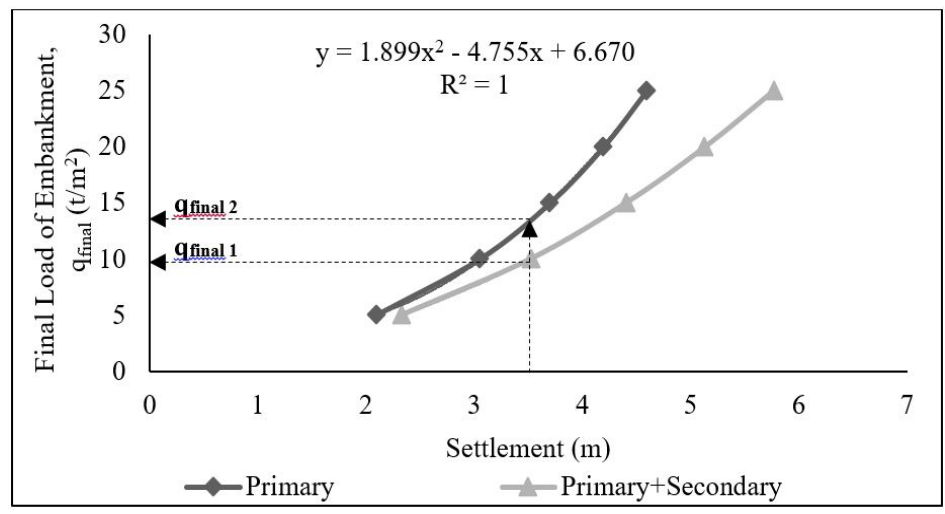

Fig. 5. The relationship between settlement and final load of embankment.

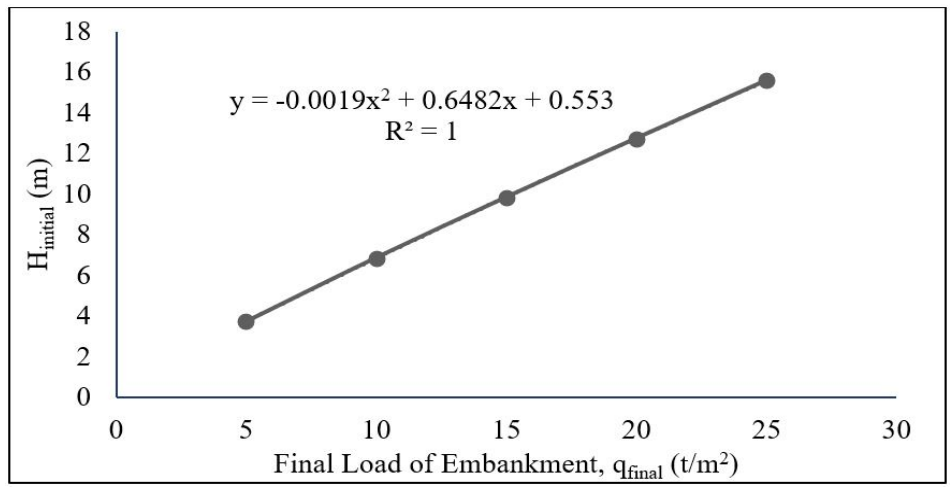

Fig. 6. The relationship between final load of embankment and initial height of embankment.

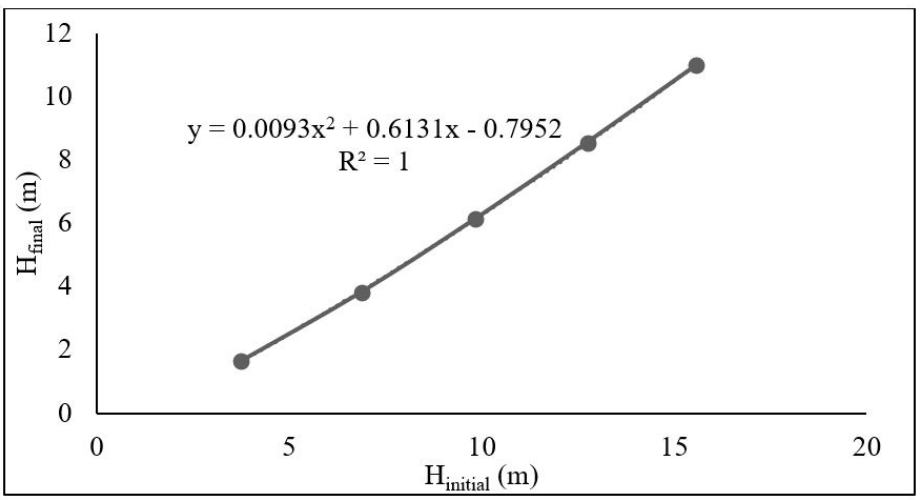

Fig. 7. The relationship between $\mathrm{H}_{\text {initial }}$ and $\mathrm{H}_{\text {final. }}$.

Examples of $\mathrm{H}_{\text {initial }}$ and $\mathrm{H}_{\text {final }}$ calculations with $\mathrm{q}_{\text {final }}=10 \mathrm{t} / \mathrm{m}^{2}$ are as follows:

- The total of primary and secondary compression, $\mathrm{S}_{\text {total }}$

from the calculation of settlement with $\mathrm{q}_{\text {final }}=10 \mathrm{t} / \mathrm{m}^{2}$ is obtained $\mathrm{S}_{\text {total }}=3.52 \mathrm{~m}$

- The New final load of embankment, $\mathrm{q}_{\text {final } 2}$

from the equation Figure 5 at the primary consolidation curves, with $S_{\text {total }}=3.52 \mathrm{~m}$ is obtained:

$\mathrm{y} \quad=1.899 \mathrm{x}^{2}-4.755 \mathrm{x}+6.670=1.899(3.52)^{2}-4.755(3.52)+6.670$
$\mathrm{q}_{\text {final } 2}=13.46 \mathrm{t} / \mathrm{m}^{2}$ 
- The extra load of embankment to remove the secondary compression, $\Delta \mathrm{q}$

$\mathrm{q}_{\text {final } 1}=10 \mathrm{t} / \mathrm{m}^{2}$

$\Delta \mathrm{q}=\mathrm{q}_{\text {final } 2}-\mathrm{q}_{\text {final } 1}=13.46-10 \mathrm{t} / \mathrm{m}^{2}=3.46 \mathrm{t} / \mathrm{m}^{2}$

- The Initial height of embankment before primary and secondary compression occurs, $\mathrm{H}_{\text {initial }(\mathrm{p}+\mathrm{s})}$

from the equation Figure 6 , with $\mathrm{q}_{\text {final } 2}=13.46 \mathrm{t} / \mathrm{m}^{2}$ is obtained :

$$
\begin{array}{ll}
\mathrm{y} & =-0.0019 \mathrm{x}^{2}+0.6482 \mathrm{x}+0.553=-0.0019(13.46)^{2}+0.6482(13.46)+0.553 \\
\mathrm{H}_{\text {initial }(\mathrm{p}+\mathrm{s})} & =8.93 \mathrm{~m}
\end{array}
$$

- The Final height of embankment after primary and secondary compression occurs,

$$
\mathrm{H}_{\text {final }(\mathrm{p}+\mathrm{s})}
$$

from the equation Figure 7, with $\mathrm{H}_{\text {initial }}=8.93$ is obtained :

$$
\begin{array}{ll}
\mathrm{y} & =0.0093 \mathrm{x}^{2}+0.6131 \mathrm{x}-0.7952=0.0093(8.93)^{2}+0.6131(8.93)-0.7952 \\
\mathrm{H}_{\text {final }(\mathrm{p}+\mathrm{s})} & =5.42 \mathrm{~m}
\end{array}
$$

- The final height of embankment in the field after unloaded, $\mathrm{H}_{\text {final-field }}$

$$
\begin{aligned}
& \gamma_{\text {timbunan }}=1.9 \mathrm{t} / \mathrm{m}^{3} ; \mathrm{H}_{\text {final }(\mathrm{p}+\mathrm{s})}=5.42 \mathrm{~m} ; \Delta \mathrm{q}=3.46 \mathrm{t} / \mathrm{m}^{2} \\
& \mathrm{H}_{\text {final-field }}=\mathrm{H}_{\text {final }(\mathrm{p}+\mathrm{s})}-\Delta \mathrm{q} / \gamma_{\text {timbunan }}=5.42-3.46 / 1.9=3.6 \mathrm{~m}
\end{aligned}
$$

In the same way as above, the calculations are continued on all $\mathrm{q}_{\text {final }}$ variations. The result of the calculation $\mathrm{H}_{\text {final-field }}$ and $\mathrm{H}_{\text {initial }(\mathrm{p}+\mathrm{s})}$ can be seen in the graph of the relationship between $\mathrm{H}_{\text {final-field }}$ and $\mathrm{H}_{\text {initial }(\mathrm{p}+\mathrm{s})}$ is obtained as presented in Figure 8.

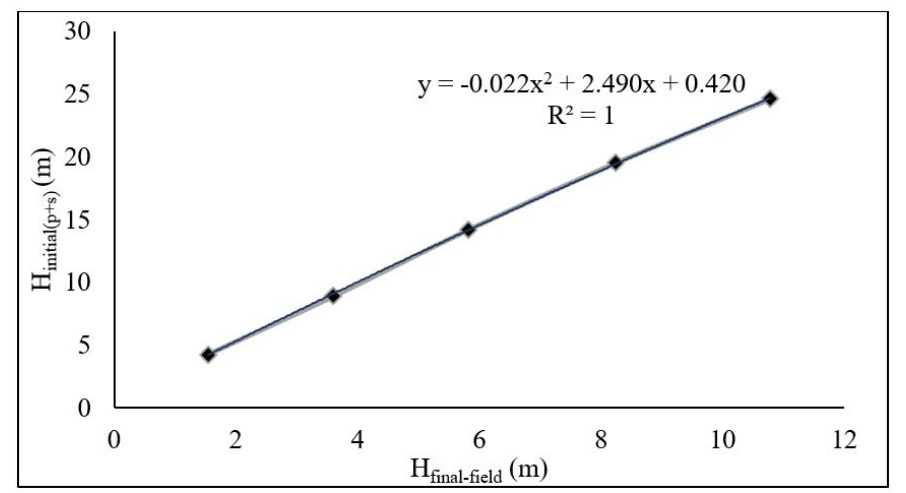

Fig. 8. The relationship between $\mathrm{H}_{\text {final-field }}$ and $\mathrm{H}_{\text {initial }(\mathrm{p}+\mathrm{s}) \text {. }}$

The graph of the relationship between $\mathrm{H}_{\text {final-field }}$ with $\mathrm{H}_{\text {initial }(\mathrm{p}+\mathrm{s})}$ in Figure 8 is later used as a guide for determining the initial height of embankment in preloading to remove the primary consolidation and secondary compression in the same time. By inputting the $\mathrm{H}_{\text {final-field }}$ value in the equation of Figure $8, \mathrm{H}_{\text {initial }}$ will be obtained. The $\mathrm{H}_{\text {final-field }}$ is the height of the embankment designed on the elevation plan in the field.

\section{Conclusion}

Based on laboratory experimental studies and statistical analysis, there are empirical correlations between the secondary compression index $\left(\mathrm{C} \alpha^{\prime}\right)$ with the initial void ratio $\left(\mathrm{e}_{0}\right)$, the void ratio at the end of primary consolidation $\left(\mathrm{e}_{\mathrm{p}}\right)$, and the effective consolidation stress $\left(\mathrm{P}^{\prime}\right)$. Regression between $\mathrm{C} \alpha$ '- $\mathrm{e}_{0}-\mathrm{P}^{\prime}$ and $\mathrm{C} \alpha^{\prime}-\mathrm{e}_{\mathrm{p}}-\mathrm{P}^{\prime}$ shows a strong correlation between these parameters. Based on the linear regression, the relationship of $\mathrm{C} \alpha{ }^{\prime}-\mathrm{e}_{0}-\mathrm{P}^{\prime}$ has the coefficient of determination is $\mathrm{R}=0.888$, while for the relation $C \alpha^{\prime}-\mathrm{e}_{\mathrm{p}}-\mathrm{P}^{\prime}$ has $\mathrm{R}=0.914$. With a fairly high $\mathrm{R}$ value of close to 1 , this empirical correlation can be used in predicting the secondary compression index. The correlations obtained from this study are as follows: 
$C \alpha^{\prime}=\left(0.0072 e_{0}-0.0067\right) P^{\prime}$ and $C \alpha^{\prime}=\left(0.0077 e_{p}-0.006\right) P^{\prime}$

where: $\mathrm{C} \alpha^{\prime}$ is the secondary compression index, $\mathrm{e}_{0}$ is the initial void ratio, $\mathrm{e}_{\mathrm{p}}$ is the void ratio at the end of primary consolidation, and $\mathrm{P}^{\prime}$ is the effective consolidation stress which is the magnitude of the addition of stress due to the external load $(\Delta \mathrm{P}), \mathrm{P}^{\prime}=\Delta \mathrm{P}$.

The value of the secondary compression index $\left(\mathrm{C}^{\prime}\right)$ is influenced by the effective consolidation stress ( $\left.\mathrm{P}^{\prime}\right)$. The greater the effective consolidation stress ( $\left.\mathrm{P}^{\prime}\right)$ is, then the greater the secondary compression index $\left(\mathrm{C} \alpha^{\prime}\right)$ will become. So that the secondary compression can be removed along with preloading at the time of removal of the primary consolidation. Secondary compression can be removed by giving an extra load $(\Delta \mathrm{q})$ that causes additional compression to the primary consolidation where the magnitude equals to the expected secondary compression. Then, this $\Delta \mathrm{q}$ could be removed at the end of the primary consolidation. So that after soil improvement with preloading is completed, there is no more settlement caused by primary consolidation and secondary compression. The extra load $(\Delta q)$ during preloading will make the soil become more compressive such that increases undrained shear strength value $(\mathrm{Cu})$. The increasing value of $\mathrm{Cu}$ causes the secondary compression index $\left(\mathrm{C} \alpha^{\prime}\right)$ to be smaller. So that the extra load $(\Delta \mathrm{q})$ at the time of preloading can eliminate the secondary compression at a certain time period.

\section{References}

1. A. Alihudien, I. B. Mochtar, Usulan Perumusan Pemampatan Konsolidasi Sekunder untuk Tanah Lempung, "Pertemuan Ilmiah Tahunan XIII 2009 Himpunan Ahli Teknik Tanah Indonesia" Proceedings, Denpasar Bali, ISBN: 978-979-96668-7-1, (2009).

2. B. M. Das, K. Sobhan, Principles of Geotechnical Engineering $8^{\text {th }}$ Edition. SI, Global Engineering: Christopher M. Shortt, 381-389, (2012).

3. C. C. Ladd, Settlement Analysis ff Cohesive Soils, Research Report R71-2. Cambridge, MA: MIT, (1994).

4. D. C. Koutsoftas, R. Foott, L. D. Handfelt, Geotechnical Investigations Offshore Hong Kong, J. Geotech. Engng. Div., ASCE 113, No. 2, 87-105, (1987).

5. E. E. Alonso, A. Gens, A. Lloret, Precompression Design for Secondary Settlement Reduction, Geotechnique 50, No. 6, 645-656, (2000).

6. G. Mesri, Coeffisient of secondary Compression, Journal of the Soil Mechanics and Foundations Divisions. Proc. ASCE Vol. 99 No. SM1, pp 123-137, (1973).

7. G. Mesri, M. A. Ajlouni, T. W. Feng, D. O. K. Lo, Surcharging of Soft Ground to Reduce Secondary Settlement, U.S.A, Republic of China, (1973).

8. I. B. Mochtar, Empirical Parameters for Soft Soil in Situ, Civil Engineering DepartmentITS, (2006) and Revised (2012).

9. I. B. Mochtar, Teknologi Perbaikan Tanah dan Alternatif Perencanaan pada Tanah Bermasalah (Problematic Soils), Civil Engineering Department-ITS, 126, (2002).

10. J. Chu, B. Indraratna, S. Yan, C. Rujikiatkamjorn, Practical Considerations for Using Vertical Drains in Soil Improvement Projects, Proceedings of the Institution of Civil Engineers: Ground Improvement, 167 (3), 173-185, (2014).

11. K. P. Yu, R. P. Frizzi, Preloading Organic Soils to Limit Future Settlements. In Vertical and Horizontal Displacements of Foundations and Embankments, ASCE Geotechnical Special Publication No. 40, 1, 476-490, (1994). 